\title{
Combination of endoscopic-ultrasound guided choledochoduodenostomy and gastrojejunostomy resolving combined distal biliary and duodenal obstruction
}

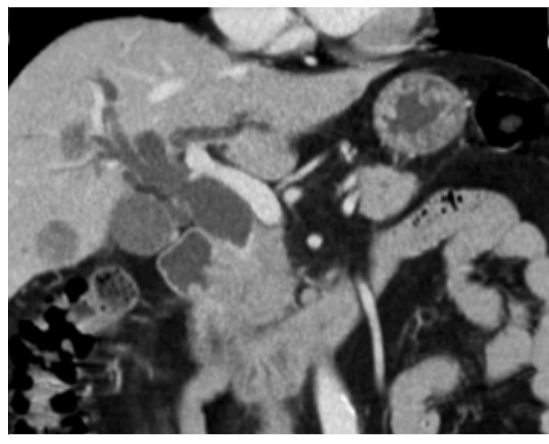

Fig. 1 Computed tomography revealed a $3.5 \times 3.5 \times 3.2-\mathrm{cm}$ heterogeneous enhancing periampullary mass with adjacent bowel wall invasion at the second part duodenum, causing luminal narrowing of the second part duodenum and upstream dilatation of the common bile duct.

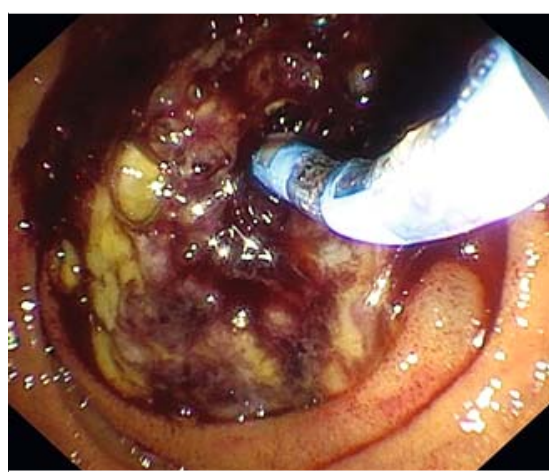

- Fig. 2 A large friable ampullary mass causing supra-ampullary duodenal obstruction.

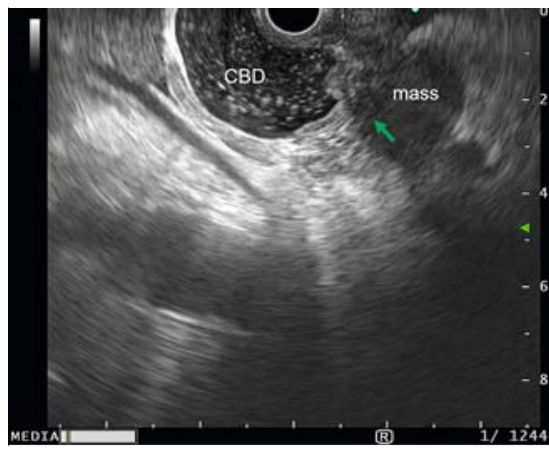

- Fig. 3 Endoscopic ultrasound revealed a periampullary mass (mass) with a dilated common bile duct (CBD).

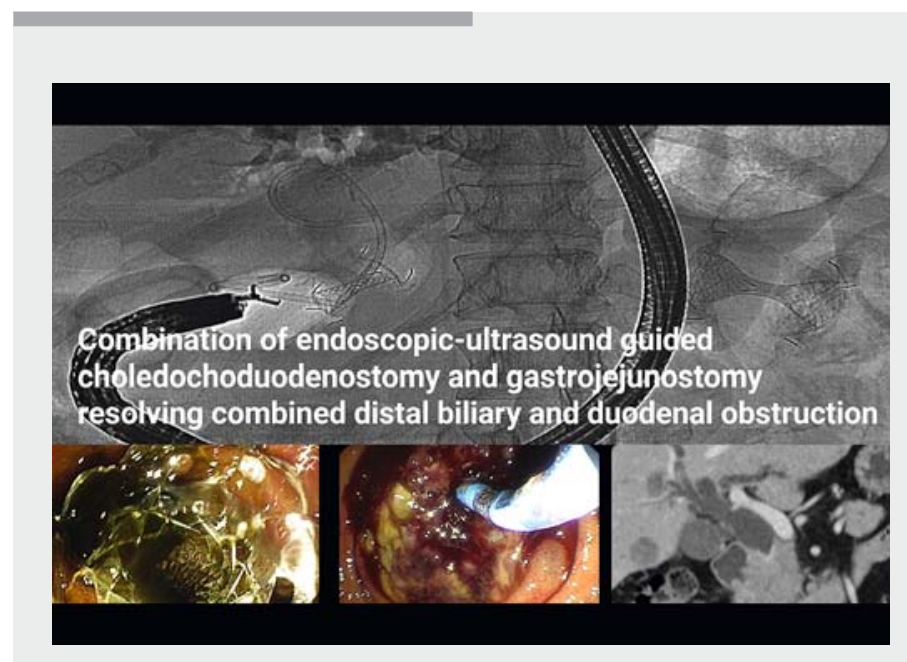

Video 1 Endoscopic-ultrasound guided choledochoduodenostomy and gastrojejunostomy resolving combined distal biliary and duodenal obstruction in patient with periampullary cancer.

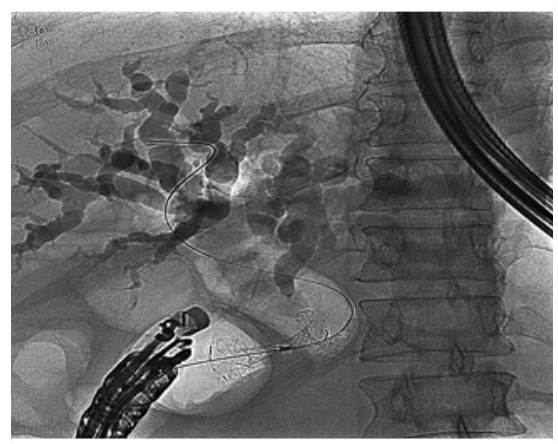

- Fig. 4 An $8 \times 12$-mm lumen-apposing metal stent (LAMS) was successfully placed transduodenally into the distal common bile duct.

A 68-year-old man presented with abdominal pain, jaundice, and weight loss for 1 month. Abdominal computed tomography revealed a periampullary mass measuring $3.5 \times 3.5 \times 3.2 \mathrm{~cm}$ with dilated bile duct ( $\triangleright$ Fig. 1).

An endoscopic retrograde cholangiopancreatography (ERCP) procedure was not possible owing to a large friable ampullary mass causing supra-ampullary duodenal obstruction ( $\mathbf{F i g} \mathbf{2}$ ). An endo-



- Fig. 5 A 16×20-mm lumen-apposing metal stent (LAMS) was successfully placed transgastrically into the lumen of the jejunum.

scopic ultrasound-guided choledochoduodenostomy (EUS-CDS) was consequently performed ( $\downarrow$ Video 1 ) with a linear echoendoscope (GF-UCT180; Olympus, Aizu, Japan). A dilated distal common bile duct (CBD) from an ampullary was shown (> Fig.3). A 19-gauge endoscopic ultrasound-guided fine-needle aspiration (EUS-FNA) needle (Echotip Ultra; Cook Medical Ltd., Limerick, Ireland) with an angled 0.025 -inch guide- 
wire (Visiglide 2, Olympus) was used for puncturing. A 6-Fr cystotome (EndoFlex, Voerde, Germany) and a 4-mm balIoon dilatation catheter (Hurricane RX; Boston Scientific, Cork, Ireland) were used for dilation. An $8 \times 12$-mm lumenapposing metal stent (LAMS) (Niti-S Spaxus; Taewoong Medical Co., Ilsan, Korea) was successfully placed transduodenally into the distal CBD ( $\vee$ Fig.4). Subsequently, an EUS-guided gastrojejunostomy was performed. A 10-Fr nasobiliary catheter (Flexima; Boston Scientific, Marlborough, Massachusetts, USA) was placed into the jejunum to flush a mix of diluted contrast, saline, and methylene blue into the lumen of the jejunum in order to distend the small bowel loop. A $16 \times 20-m m$ LAMS with an electrocautery delivery system (Niti-S Spaxus; Taewoong Medical Co.) was successfully placed transgastrically into the lumen of the jejunum ( $\triangleright$ Fig. 5). The patient resumed diet with a decline of bilirubin level at 48 hours after the procedure without adverse events.

This case reported the feasibility of a combination of EUS-guided choledochoduodenostomy and EUS-guided gastrojejunostomy to resolve a problem of bile duct and duodenal obstruction type II [1]. Previously, most literature used a combination of EUS-guided biliary drainage and duodenal stents with a technical and clinical success rate of $71.4 \%$ to $100 \%$ and $94.1 \%$ to $100 \%$, respectively [2]. Future study to compare the efficacy of a combined EUS-guided biliary drainage with EUS-guided gastrojejunostomy versus EUS-guided biliary drainage with a duodenal stent is warranted.

Endoscopy_UCTN_Code_TTT_1AS_2AD
Competing interests

The authors declare that they have no conflict of interest.

The authors

Pradermchai Kongkam ${ }^{1,2}$, Thanawat Luangsukrerk' ${ }^{1}$, Kamin Harinwan ${ }^{3}$, Kunvadee Vanduangden', Suppawatsa Plaidum', Rungsun Rerknimitr ${ }^{1}$, Pinit Kullavanijaya ${ }^{1}$

1 Gastrointestinal Endoscopy Excellence Center, Department of Medicine, Faculty of Medicine, Chulalongkorn University and King Chulalongkorn Memorial Hospital, Thai Red Cross Society, Bangkok, Thailand

2 Pancreas Research Unit, Department of Medicine, Faculty of Medicine, Chulalongkorn University, Bangkok, Thailand

3 Division of Gastroenterology, Department of Medicine, Faculty of Medicine, Phramongkutklao Hospital, Phramongkutklao College of Medicine, Bangkok, Thailand

\section{Corresponding author}

\section{Thanawat Luangsukrerk, MD}

Gastrointestinal Endoscopy Excellence Center, Chulalongkorn University and King Chulalongkorn Memorial Hospital, Thai Red Cross Society, 1873, Rama 4 Road, Patumwan, Bangkok, Thailand 10500 Fax: +66-2-652-4219 drthanawat|@gmail.com

\section{References}

[1] Mutignani M, Tringali A, Shah SG et al. Combined endoscopic stent insertion in malignant biliary and duodenal obstruction. Endoscopy 2007; 39: 440-447

[2] Mangiavillano B, Khashab MA, Tarantino I et al. Success and safety of endoscopic treatments for concomitant biliary and duodenal malignant stenosis: a review of the literature. World J Gastrointest Surg 2019; 11: 53-611

\section{Bibliography}

Endoscopy 2021; 53: E355-E356

DOI 10.1055/a-1294-9399

ISSN 0013-726X

published online 19.11 .2020

(c) 2020. Thieme. All rights reserved.

Georg Thieme Verlag KG, Rüdigerstraße 14, 70469 Stuttgart, Germany

\section{ENDOSCOPY E-VIDEOS \\ https://eref.thieme.de/e-videos}

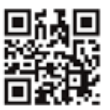

Endoscopy E-Videos is a free access online section, reporting on interesting cases and new

techniques in gastroenterological endoscopy. All papers include a high quality video and all contributions are freely accessible online.

This section has its own submission website at https://mc.manuscriptcentral.com/e-videos 